\title{
Economic policy uncertainty and growth nexus in Pakistan: a new evidence using NARDL model
}

\author{
Jun Wen ${ }^{1} \cdot$ Samia Khalid ${ }^{1} \cdot$ Hamid Mahmood $^{1} \cdot$ Xiuyun Yang $^{1}$
}

Received: 7 November 2020 / Accepted: 29 October 2021 / Published online: 13 November 2021 (C) The Author(s), under exclusive licence to Springer Science+Business Media, LLC, part of Springer Nature 2021

\begin{abstract}
This study aims to test the symmetric and asymmetric impact of economic policy uncertainty (EPU) on economic growth for the time period 2011M1-2020M5 in Pakistan, using the linear and nonlinear autoregressive distributive lag (ARDL) approach. Unlike other studies, we aim to estimate the impact of uncertainty using the recently developed EPU index by Baker et al. (Q J Econ 131(4):1593-1636, 2016). The nonlinear (NARDL) model results show that positive EPU shocks have a negative impact on short-run economic growth, and the magnitude of positive shocks is greater than the magnitude of negative shocks. The reason is that Pakistan is facing issues like nondiversified sectors, price spikes, political uncertainty, and a weak economic and financial structure. Due to these factors, any adjustment in economic policies creates an unpredictable environment in the country. When uncertainty decreases, economic activity may rebound, but it does not happen instantly. On the basis of the findings of the study, we recommend that there should be political stability in the country and coordination between macroeconomic policies to achieve long-term goals. Moreover, policymakers must play their part in reducing levels of uncertainty by envisaging any future changes in the policy-regulatory environment and maintaining the flexibility to act quickly in the event of a major economic crisis.
\end{abstract}

Keywords Policy uncertainty $\cdot$ Growth $\cdot$ NARDL

Hamid Mahmood

hamid.xjtu@gmail.com

Jun Wen

wjun1978@163.com

Samia Khalid

samiakhalid3@gmail.com

Xiuyun Yang

Yangxiuyun@mail.xjtu.edu.cn

1 School of Economics and Finance, Xi' an Jiaotong University, Xi'an, Shaanxi,

People's Republic of China 
JEL Classification C22 - D82 - O40

\section{Introduction}

In today's interconnected world, the importance of uncertainty in policies related to economic decision making is greater than ever. Previous decades have witnessed substantial changes in the economic environment, structures, and policies all around the world. This has created an uncertain economic environment for investment and resource allocation. According to Handley and Limao (2015), the impact of EPU on economic growth is much stronger as compared to monetary or fiscal policies. Uncertainty about consumption/investment plans not only affects future investment decisions, but it also has a significant impact on developing countries' economic growth (Bloom 2009; Pastor and Veronesi 2012). Economic uncertainty is prominent in developing countries due to asymmetric information, low production levels and a lack of technological progress. Therefore, they have a greater dependence on the policies and programs designed by developed countries and international financial institutions. Economic uncertainty occurs due to the disparity and discontinuity of government policies, which is worsened due to frivolous feedback from policymakers toward a changing economic environment and policy objectives. In recent times, the debate over EPU has become more important because the economic impact of these policies has changed since the 1970s, especially in developing countries. Therefore, we do find voluminous literature pertaining to gauging the impact of uncertainty in the case of developed and developing countries (Aizenman and Marion 1993a; b; Servén 1998; Lensink et al. 1999; Serven 2002; Jeong 2002; Asteriou and Price 2005; Fountas and Karanasos 2006; Fountas et al. 2006; Pastor and Veronesi 2012; Handley and Limao 2015).

Recently, Baker et al. (2016) developed a new index to measure EPU, which is based on newspaper coverage frequency. The existing literature has empirically investigated the impact of uncertainty on output and employment (Bloom 2009), economic growth (Bhagat et al. 2013; Fatima and Waheed 2014; Karnizova and Li 2014; Ren et al. 2020), unemployment (Baker et al. 2016), investment (Wang et al. 2014; Abbas et al. 2019), trade (Tam 2018), innovation (Jiandong and Khan 2018) and tourism (Işık et al. 2020; Ghosh 2020). On the other hand, there are also some studies which have explored the effects of uncertainty using the EPU index on goods prices, particularly food prices (Wen et al. 2021), oil (Kang and Ratti 2013; Antonakakis et al. 2014; Bekiros et al. 2016; Yin 2016; Wang and Sun 2017; Kang et al. 2017), industrial economic growth (Chen et al. 2019), gold (Fang et al. 2018; Raza et al. 2018) and stocks (Ko and Lee 2015; Das and Kumar 2018; Liang et al. 2020). In case of Pakistan, there is limited literature available regarding the impact of uncertainty on different macroeconomic variables. The notable contributions in this regard include Ahmad and Qayyum (2008, 2009), Bhatti et al. (2008), Fatima and Waheed (2014), Farooq and Yasmin (2017), Abbas et al. (2019) and Choudhary et al. (2020). The existing literature, however, mostly examines the impact of uncertainty using common models like the vector autoregressive model (VAR) and generalized autoregressive conditional heteroskedasticity $(\mathrm{GARCH})$. After the pioneering 
work of Baker et al. (2016), the attention of researchers has been directed toward a measure based on economic uncertainty issues.

Pakistan, as a developing country, is experiencing sluggish economic growth owing to frequent changes in governments, an uncertain political environment, and economic policies. This sluggish growth has intensified the existing economic uncertainty and discontinuity in economic decision making. Therefore, uncertainty is severely affecting Pakistan's economy due to its weak economic and financial structure. Furthermore, little attention has been paid to the serious consequences of economic policy uncertainty. EPU shocks are sudden and unforeseen due to their asymmetric behavior. If the change in uncertainty has a symmetric effect, then it will have only short-term effects on economic growth. If it has asymmetric effects with a significant increase compared to a significant decrease, then this will cause a continuous drag on economic growth. Hence, it is important to explore the asymmetric impact of EPU on the economic growth of Pakistan.

This study has contributed to the existing literature on important grounds and aims to add a new aspect to the existing empirical literature. First, the existing studies have flaws, especially with respect to the computation of economic uncertainty. This study empirically evaluates the impact of the newly developed EPU index on economic growth during the critical period for the economy of Pakistan. Moreover, this study includes the data time period of the recent health crisis, the Covid19 outbreak. This has severely affected the recovering economy of Pakistan as well as the global economy. Secondly, previous studies have ignored the most important factor, asymmetry. Therefore, this study will also check the asymmetric impact of EPU along with the symmetric impact on economic growth. To the author's best knowledge, this is the first study to use the nonlinear autoregressive distributed lag (NARDL) approach to inspect the impact of EPU on the economic growth of Pakistan. The findings of the study can help with a better understanding of the impact of EPU, and they can also help policy makers to formulate policies for sustainable economic growth.

The study is arranged in a manner that Sect. 2 illustrates the EPU and growth trends in Pakistan. Section 3 explains the data and methodology. The empirical findings are explained in Sect. 4. Finally, Sect. 5 provides the conclusion and recommendations of the study.

\section{Economic policy uncertainty and growth trends in Pakistan}

Figure 1 shows the trend of EPU for the period 2011M1-2020M5. In terms of event analysis, the overall EPU index captures a critical period for the economy of Pakistan. Frequent changes in governments over the years have increased economic uncertainty and stagnation in economic decision making. Furthermore, for more than a couple of years in the last decade, especially from 2010 to 2012, Pakistan witnessed a bloody and intense war on terror. This war on terror and severe energy shortages can be explained in an "eventual sense" by the high level of the EPU index during the period from 2011 to mid-2012. 


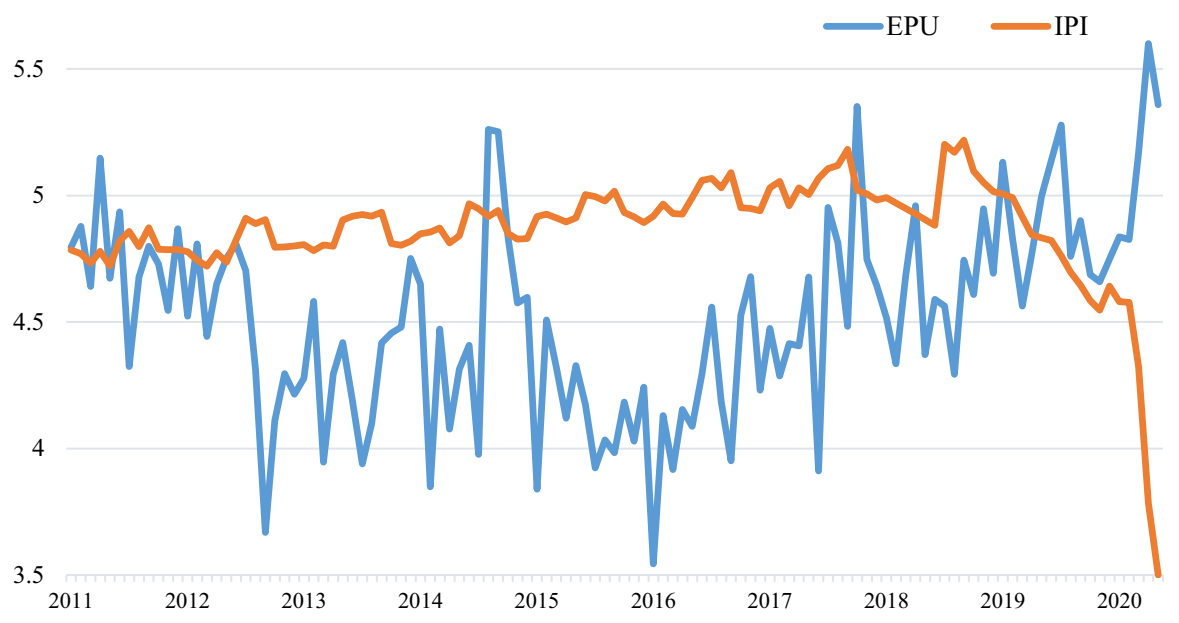

Fig. 1 EPU and IPI in Pakistan (2011M1-2020M5)

Figure 1 shows the movements of economic growth (IPI) along with uncertainty levels. It is obvious from the graph that, with lower levels of EPU, economic growth was not higher throughout the trend. But it also shows that positive changes (increase) in EPU affect growth more than negative changes (decrease) in EPU, indicating an asymmetry. The effect captured by the EPU index was not found in 2013 based on any significant event that could lead to an increase in uncertainty. However, this nationwide economic and political outlook was distorted by the opposition after the 2013 election results. During this march, the graph shows the highest level of uncertainty in the whole period from 2010 to 2020, but still, there was a factor of asymmetry. This nationwide anti-government protest, dubbed the "Independence March," came to an end in December 2014, following the tragedy at the militarypublic school in Peshawar.

At the start of the year 2015, low levels of EPU were recorded and during that year, the economy improved due to positive signs shown by major economic indicators such as inflation, fiscal balance and current account balance. Moreover, the exchange rate and oil prices were also stable and the foreign exchange reserves were recorded at an all-time high of US $\$ 18.7$ billion. ${ }^{1}$ But in 2016, the EPU was mostly low, but some negative factors, such as a widening current account deficit and rising inflation, began to grow this year, and these factors collectively led to a slight spike in the EPU. In 2017, the EPU began to pick up speed and peaked dangerously high. The beginning of 2018 was quite good, with a relatively low level of uncertainty that will arise further in the upcoming months due to political instability. Since then, uncertainty has moderated and risen again due to the presidential election in September. Later in the year, uncertainty began to rise. Deficits on the financial and external fronts, rising inflationary pressures and high aggregate demand pose

\footnotetext{
1 Economic survey of Pakistan (2015).
} 
challenges to the economy at the end of this fiscal year. Figure 1 depicts the EPU's intensifying behavior from 2018 to 2019. Moreover, there is a continuous increase in uncertainty that initially occurred due to changes in the economic situation. In addition, negotiations began with the International Monetary Fund on a bailout package to address the Equilibrium Payment imbalance. However, it was believed at the time that the International Monetary Fund's plan was inevitable and important for reviving the economy. But after mid-2019, uncertainty began to gradually subside, showing the benefits of achieving economic stability in close coordination with the International Monetary Fund and an increase in foreign exchange reserves through an increase in foreign exports (exports, remittances, capital inflows). However, at the beginning of the year 2020, the Corona Virus (COVID-19) epidemic spread from China in December 2019 and engulfed almost the entire world, including Pakistan. At that time, Pakistan's already weak economy was just beginning to stabilize, and its economic consequences significantly stymied the country's recovery by increasing economic policy uncertainty (EPU) to unprecedented highs. From analysis, we find that the cause of sluggish growth is political instability and the weak economic structure of Pakistan.

\section{Data and methodology}

The purpose of the study is to explore the asymmetric impact of EPU on economic growth in Pakistan using monthly time series data for the period from 2011M1 to 2020M5. This section comprehensively explains the variables used and a methodology that has the potential to evaluate the asymmetric response of economic activity to uncertainty. The EPU index measures economic policy uncertainty, and the industrial production index (IPI) serves as a proxy for economic growth.

\subsection{Description of variables}

\subsubsection{Economic policy uncertainty (EPU)}

Most of the existing studies illustrate the interaction between economic policy uncertainty and macroeconomic indicators of their interest. The word "economic uncertainty" is often used interchangeably to refer to real-world influences that lead to unintended and long-term economic consequences. A key component of the monthly EPU index ${ }^{2}$ is the counting of newspaper articles containing key words related to policy uncertainty (Baker et al. 2016). Moreover, EPU reflects a broader professional perspective. It could serve as a representative of expectations made by investors concerning the government's response to economic crises. In this context, a high-level EPU may indicate an absence of confidence in the capabilities of the government at a time when firm decision making is threatened in the economy

\footnotetext{
${ }^{2}$ EPU indices for many countries are regularly updated at http://www.policyuncertainty.com/.
} 
(Dakhlaoui and Aloui 2016) and concerns about the forthcoming effect of unforeseen policies or regulations regarding business performance (Kang et al. 2014). The EPU is said to pose a significant irreversible risk to individual investors within the country and predicts negative economic consequences (Brogaard and Detzel 2015). Many empirical studies show that EPU has a major impact on economic growth performance.

\subsubsection{Industrial production index (IPI)}

In short-term economic policy analysis, industrial production has its own practical importance (Ejaz and Iqbal 2019). The primary reason for this is that industrial production is more frequently accessible than gross domestic product (GDP). Moreover, industrial production provides fuel for economic activity, so it is considered to be a good proxy for overall GDP growth. Any fluctuation in industrial output provides an insight into the state of the economic cycle as consumer durables and capital output are likely to decline during the recession. Although the industrial sector accounts for only a fraction of the total output of the economy, it is an important indicator of the growth and economic performance of the GDP due to its sensitivity to consumer demand and interest rates. The industrial sector is important in defining integrated flexibility, because some service functions are closely linked to the industry (Bruno and Lupi 2004). Due to this advantage, economists regard IPI as an imperative indicator of economic activity (Banerjee et al. 2005), and it is also associated with income levels (Hettige et al. 1992).

3.1.2.1 Computation of industrial production index (IPI) In this study, we used IPI as a proxy for economic growth. In this context, a major contribution was made by Arby (2008), who proposed a process to quarterize the production side of GDP and all its sectors/sub-sectors both at the constant prices of 1999-2000 and at current prices for the period from 1972 to 2005. This was later used and extended by Hanif et al. (2013) to measure the GDP per quarter of Pakistan from 1999-2000 to 2009-2010 using a production method based on the constant prices of 1999-2000 as well as at current prices. These studies tended to concentrate only on estimating the aggregate national accounts rather than the industrial output component. But understanding short-term fluctuations in economic activity is critical. Therefore, to fill this gap, Ejaz and Iqbal $(2019)^{3}$ provided monthly estimates of industrial production for the period from July 1990 to June 2018. This newly constructed IPI ${ }^{4}$ covers Pakistan's entire industrial sector.

\footnotetext{
${ }^{3}$ Calculated data from July 1990 to June 2018.

${ }^{4}$ Where $M$ and $Q$ represent mining and quarrying, LSM and SSM represent large scale manufacturing and small-scale manufacturing, respectively, VAS and VAC represent values added by the slaughtering and cement sectors, respectively, and VAE represents values added by the energy sector. $y$ denotes the annual value added by a sector, $n$ the number of sectors, and $m$ the monthly value added by that sector.
} 


$$
\begin{aligned}
& \mathrm{IPI}_{m} \\
& =\left[\frac{M \& Q_{m, y}+\mathrm{LSM}_{m, y}+\mathrm{SSM}_{m, y}+\mathrm{VAS}_{m, y}+\mathrm{VAC}_{m, y}+\mathrm{VAE}_{m, y}}{\frac{1}{12} \sum_{m=1}^{12}\left(M \& Q_{m, 2005-06}+\mathrm{LSM}_{m, 2005-06}+\mathrm{SSM}_{m, 2005-06}+\mathrm{VAS}_{m, 2005-06}+\mathrm{VAC}_{m, 2005-06}+\mathrm{VAE}_{m, 2005-06}\right)}\right] * 100,
\end{aligned}
$$

using the above formula, we calculated the IPI index from July 2018 to June 2020.

\subsection{Estimation technique}

In the existing literature, many researchers have adopted the standard cointegration framework of error correction modeling to analyze the long-term relationship between uncertainty and variables of their interest. The aim of the study is to check the asymmetric relationship between economic growth and economic uncertainty, as mentioned above. To accomplish this, the study uses the linear and nonlinear autoregressive distributed lag (NARDL) approach developed by Shin et al. (2014). Hence, reserving all the merits of the standard ARDL, the NARDL approach is an asymmetric extension of the standard ARDL model, and it captures short-run as well as long-run asymmetry in a variable under consideration. The main advantage of this application is that, through a single equation, both asymmetry and co-integration can be determined. Furthermore, it is applicable to small sample sizes and variables with mixed order I(0) or I(1) stationarity (Ibrahim 2015; Akber and Paltasingh 2019; Ahmad et al. 2019; Ghosh 2020). Hence, the model of the study is written as follows:

$$
\mathrm{IPI}_{t}=\alpha_{0}+\alpha_{1} \mathrm{EPU}_{t}+\epsilon_{t}
$$

The IPI is the industrial production index (a proxy for measuring economic growth), and the EPU is the economic policy uncertainty index. The asymmetric form of above Eq. (1) is written as follows:

$$
\mathrm{IPI}_{t}=\beta_{0}+\beta_{1} \mathrm{POS}_{t}+\beta_{2} \mathrm{NEG}_{t}+\mu_{t} .
$$

In the above equation, $\beta_{1}, \beta_{2}$ and $\mu_{t}$ are the parameters and error term, respectively. The terms $\mathrm{POS}_{t}$ and $\mathrm{NEG}_{t}$ in the equation represent the components of asymmetry in the model, and their values can be generated by computing:

$$
\operatorname{POS}_{t}=\sum_{j=1}^{t} \Delta \mathrm{EPU}_{j}^{+}=\sum_{j=1}^{t} \max \left(\Delta \mathrm{EPU}_{j}, 0\right)
$$

and

$$
\mathrm{NEG}_{t}=\sum_{j=1}^{t} \Delta \mathrm{EPU}_{j}^{-}=\sum_{j=1}^{t} \min \left(\Delta \mathrm{EPU}_{j}, 0\right)
$$

where the $\mathrm{POS}_{t}$ captures the positive changes in EPU and the $\mathrm{NEG}_{t}$ captures the negative changes in EPU. As mentioned above, the effect of EPU on economic growth can be asymmetric and this is captured through $\beta_{1}$ and $\beta_{2}$ in Eq. (2). The 
Table 1 Descriptive statistics analysis (2011M1-2020M5)

\begin{tabular}{lllllllllr}
\hline & Unit & Obs. & Min & Max & Mean & Std. dev & Skewness & Kurtosis & Jarque-Bera (JB) \\
\hline IPI & Index & 113 & 3.49 & 5.23 & 4.87 & 0.22 & -3.34 & 20.21 & $120.61 * * *(0.00)$ \\
EPU & Index & 113 & 3.54 & 5.60 & 4.52 & 0.39 & 0.11 & 2.89 & $59.6^{* * *}(0.00)$ \\
\hline
\end{tabular}

*** Indicates significance at $1 \%$ significance level

Table 2 Correlation matrix

\begin{tabular}{lcc}
\hline & IPI & EPU \\
\hline IPI & 1 & \\
EPU & $-0.403 * * *$ & 1 \\
\hline$* * *$ Shows significance at $1 \%$ level &
\end{tabular}

hypothesis $\beta_{1}=\beta_{2}$ specifies no asymmetry, while the alternative $\beta_{1} \neq \beta_{2}$ shows an asymmetry between the IPI and EPU movements.

According to Shin et al. (2014), the modified form of Eq. (2) in a NARDL bound test setting is shown below:

$$
\Delta \mathrm{IPI}_{t}=\gamma_{0}+\gamma_{1} \mathrm{IPI}_{t-1}+\gamma_{2} \mathrm{POS}_{t-1}+\gamma_{3} \mathrm{NEG}_{t-1}+\sum_{i=1}^{n 1} \delta_{i} \Delta \mathrm{IPI}_{t-i}+\sum_{j=1}^{n 2}\left(\rho_{j} \Delta \mathrm{POS}_{t-j}+\vartheta_{j} \Delta \mathrm{NEG}_{t-j}\right)+\varepsilon_{t} .
$$

In the above equation, $\gamma_{1}, \gamma_{2}$ and $\gamma_{3}$ represent the long-run parameters, whereas $\delta_{i}, \rho_{j}, \vartheta_{j}$ are the parameters of the short run. The null hypothesis of no cointegration $\mathrm{H}_{0}: \gamma_{1}=\gamma_{2}=\gamma_{3}=0$ between the variables in Eq. (3) is tested against the alternative hypothesis $\mathrm{H}_{1}: \gamma_{1} \neq \gamma_{2} \neq \gamma_{3} \neq 0$ cointegration among the variables. There will be cointegration among the variables if the calculated $F$-test statistic is more than the respective upper bound critical values. Hence, the null hypothesis is rejected. Similarly, in the second case, there will be no cointegration if the estimated $F$-statistic is less than the respective lower bound critical values. Therefore, we will not reject $\mathrm{H}_{0}$. The next step is to obtain short-run parameters with error correction term (ECT) to identify the required speed of adjustment. The short-run model is given below:

$$
\Delta \mathrm{IPI}_{t}=\sigma \mathrm{ECT}_{t-1}+\sum_{i=1}^{n 1} \delta_{i} \Delta \mathrm{IPI}_{t-i}+\sum_{j=1}^{n 2}\left(\rho_{j} \Delta \mathrm{POS}_{t-j}+\vartheta_{j} \Delta \mathrm{NEG}_{t-j}\right)+\varepsilon_{t},
$$

$\mathrm{ECT}_{t-1}$ is the error correction term. It identifies the divergence from equilibrium after a short-run shock and defines the pace at which the divergence must be adjusted in order to return to long-run equilibrium. In the end, the presence of shortrun and long-run asymmetry will be checked by applying the Wald test. 
Table 3 Unit-root tests

\begin{tabular}{llllllll}
\hline Variables & \multicolumn{2}{l}{ Augmented Dickey-Fuller test (intercept) } & & \multicolumn{3}{l}{ Phillips-Perron test (intercept) } \\
\cline { 2 - 3 } & Level & First difference & Decision & & Level & First difference & Decision \\
\hline IPI & -0.10 & $-10.61^{* *}$ & $\mathrm{I}(1)$ & & -3.06 & $-7.34^{* *}$ & $\mathrm{I}(1)$ \\
EPU & $-5.13^{* *}$ & - & $\mathrm{I}(0)$ & & $-5.73^{* *}$ & - & $\mathrm{I}(0)$ \\
\hline
\end{tabular}

**Shows statistical significance at $5 \%$ level

Table 4 Unit-root test with structural break

\begin{tabular}{lllllll}
\hline \multicolumn{2}{l}{ Zivot-Andrews (1992) test } & & & \\
\hline Variables & At level & & & At 1st diff & & Decision \\
\cline { 2 - 3 } \cline { 5 - 6 } & Break year & $t$-statistic & & Break year & $t$-statistic & \\
\hline IPI & $2018 \mathrm{M} 12$ & -4.21 & $2018 \mathrm{M} 7$ & $-6.89 * *$ & $\mathrm{I}(1)$ \\
EPU & $2015 \mathrm{M} 7$ & $-5.64 * *$ & - & - & $\mathrm{I}(0)$ \\
\hline
\end{tabular}

**Shows significance at $5 \%$ level

\section{Empirical analysis}

To inspect the impact of economic uncertainty on economic growth in Pakistan, the data were collected from 2011M1 to 2020M5. The summary statistics for the related variables IPI and EPU are presented in Table 1. The mean value of both variables is close, which shows that there is a symmetrical distribution. According to skewness statistics, the IPI is negatively and the EPU is positively skewed. The correlation matrix in Table 2 indicates a strong correlation between IPI and EPU. The correlation between IPI and EPU is -0.403 , which is negative and statistically significant at $1 \%$.

\subsection{Unit-root test results}

The prerequisite for carrying out econometric analysis of time series data is to test the relevant series for the order of integration. In doing so, we use the augmented Dickey-Fuller (ADF) and Phillips-Perron (PP) tests of stationarity. Table 3 shows the results of unit-root tests, which confirm that there is a mixed order of integration. The EPU is tested to be stationary at I(0), and the IPI is at the first difference, I(1).

Sometimes, due to a structural break in time series data, the accuracy of the unit-root test cannot be determined. So, we have used the Zivot-Andrews (1992) test to check the stationarity of data in the presence of structural breaks and the 
Table 5 Bounds test for co-integration

\begin{tabular}{lll}
\hline & ARDL model & NARDL model \\
\hline F-statistic & $5.97 * *$ & $9.89 * *$ \\
Critical values & & \\
Upper bound $\mathrm{I}(1)$ & 5.73 & 4.85 \\
Lower bound $\mathrm{I}(0)$ & 4.94 & 3.79 \\
\hline
\end{tabular}

**Indicates that the value is statistically significant at $5 \%$ level

Table 6 Short-run results of NARDL model (dependent variable: IPI)

\begin{tabular}{|c|c|c|c|c|}
\hline \multirow[t]{2}{*}{ Variable } & \multicolumn{2}{|c|}{ ARDL results } & \multicolumn{2}{|c|}{ NARDL results } \\
\hline & Coefficient & Std. error & Coefficient & Std. error \\
\hline$C$ & $0.629 * * *$ & 0.224 & 5.190 & 8.683 \\
\hline$\Delta \mathrm{EPU}$ & $-0.074 * *$ & 0.03 & - & - \\
\hline$\Delta \mathrm{EPU}+$ & & & $-0.125 * * *$ & 0.039 \\
\hline$\Delta$ EPU- & & & 0.037 & 0.060 \\
\hline ECT & $-0.058 * * *$ & 0.015 & $-0.064 * * *$ & 0.022 \\
\hline \multicolumn{3}{|c|}{ Wald test (asymmetry) } & \multicolumn{2}{|l|}{$5.902(0.01)$} \\
\hline
\end{tabular}

Residual diagnostic and model stability test

\begin{tabular}{lc}
\hline Test applied & $p$ value \\
\hline Breusch-Godfrey LM test & 0.700 \\
Breusch-Pagan-Godfrey test & 0.694 \\
Variance inflation factor test & 1.009 \\
Ramsey RESET test & 0.516 \\
\hline
\end{tabular}

$p$ value reported in the parenthesis ()

$* * *, * *$ Indicates that the value is statistically significant at $1 \%$ and $5 \%$ level

results are presented in Table 4. The findings are parallel with the ADF and PP test results. This provides certification to move ahead with the ARDL cointegration estimation approach.

\subsection{Bounds test for cointegration}

The results of the bounds test for both the ARDL and NARDL models are shown in Table 5. The $F$-statistic value of the ARDL model is 5.97 and for the NARDL model is 9.89 , respectively. Both values are greater than the upper bound and lower bound critical values at the 5\% significance level. Hence, it confirms that the co-integration exists, and we can proceed further. 
Table 7 Long-run results of NARDL model (dependent variable: IPI)

\begin{tabular}{llllll}
\hline Variable & \multicolumn{2}{l}{ ARDL results } & & \multicolumn{2}{l}{ NARDL results } \\
\cline { 2 - 3 } \cline { 5 - 6 } \cline { 5 - 6 } & Coefficient & Std. error & & Coefficient & Std. error \\
\hline IPI $(-1)$ & 0.041 & 0.026 & & 0.064 & 0.343 \\
EPU & $-2.704^{* *}$ & 1.246 & & - \\
EPU+ & - & - & -0.995 & 0.736 \\
EPU- & - & - & -0.460 & 0.684 \\
Wald test (asymmetry) & & $1.534(0.215)$ & \\
\hline
\end{tabular}

$p$ value reported in the parenthesis ()

**Indicates that the value is statistically significant at $5 \%$ level

\subsection{Discussion of empirical results}

Table 6 illustrates the results of long-run estimates of the ARDL (symmetric) and NARDL (asymmetric) models. To differentiate between the symmetric and asymmetric impact of EPU, the study also employed the ARDL model. According to the short-run ARDL results, the estimated coefficient of EPU was found to be negative and significant at the 5\% significance level. It shows that a $1 \%$ increase in EPU is expected to decrease the IPI by $7.4 \%$. The negative impact of EPU on economic growth is consistent with the findings of earlier studies such as Bloom et al. (2007), Handley and Limao (2015), Barrero et al. (2017) and Chen et al. (2019). These studies document a negative relationship between EPU and economic growth. Due to an increase in economic uncertainty, households/investors have postponed their future consumption/investments. This ultimately causes a negative shock in production, which ultimately leads to a fall in economic growth. According to Fatima and Waheed (2014) and Choudhary et al. (2020), Pakistan is facing issues like nondiversified sectors, price spikes, political uncertainty and a weak economic and financial structure. Due to these factors, any adjustment in economic policies creates an unpredictable environment in the country. This not only deteriorates the country's investment climate but also has a negative impact on economic growth.

The NARDL results reveal the existence of an asymmetric relationship between the EPU and the IPI. The Wald test statistic rejects the null hypothesis of having a symmetric effect of EPU on IPI and confirms the presence of shortrun asymmetry. The IPI for EPU increase is found to be negative, while the EPU decrease is found to be positive. The estimated coefficient for the positive shock of EPU is - 0.125, which shows that a $1 \%$ increase in EPU is expected to decrease economic growth by $12.5 \%$. However, the impact of the negative shock of EPU is positive but insignificant. This shows that the decrease in EPU has not had a significant impact on the growth of Pakistan. Due to the weak economic structure, nondiversified sectors and political instability in Pakistan, the increase in EPU shocks has a severe effect on the economy, but whenever EPU decreases, there is not a favorable and significant impact on growth. Therefore, whenever uncertainty decreases, economic activity may rebound, but not immediately. Moreover, 
the findings also confirm the asymmetric nature of the EPU shocks. Because they are sudden and are caused as a result of any uncertain event. This creates an uncertain environment for investors in the country, which not only reduces current investment and economic growth, but also affects economic growth and future decisions regarding investment.

The coefficient of the ECT of both models is -0.058 and -0.064 , respectively. This points out that economic growth adjusts toward its long-run equilibrium at a slow speed of $5.8 \%$ and $6.4 \%$ in the presence of EPU. Therefore, more time is required to correct the divergence and to achieve sustainable growth in the long run. The reason for the slow speed of adjustment is political instability and weak economic conditions in Pakistan. In the end, Table 6 also reports the diagnostic tests to check for suitability of the model. The results of all the diagnostic tests confirm the model stability, absence of autocorrelation, heteroskedasticity and multicollinearity in the model.

Table 7 in this section shows the long-run results of the ARDL and NARDL models. The long-run estimated coefficient of EPU is found to be negative and significant at 5\%. This shows that a $1 \%$ increase in EPU is associated with a decrease in EPU by $2.7 \%$. On the other hand, the NARDL results show a negative and insignificant impact of EPU positive and negative shocks on the IPI. Here, the Wald test statistic shows no evidence of asymmetry.

The above analysis shows the asymmetric impact of the EPU on economic growth over the long run and in the short run. In the ARDL model results, elasticities are found to be negative and statistically higher in magnitude both in the short run and in the long run. However, in the NARDL model results, the positive and negative components of both the short-run elasticities of EPU are negative and positive, indicating a negative relationship. However, in the long run, the scenario is quite different. Thus, considering these facts, we conclude the strong and negative impact of EPU on the economic output of Pakistan. To overcome the adverse effects of uncertainty, influential aspects like effective government policy, political stability and terms of trade must be ensured.

\section{Concluding remarks}

The last decade has seen various stages of dramatic fluctuations in Pakistan's economy. When examining aspects of these dramatic changes in macroeconomic indicators, existing studies often ignore the role of economic uncertainty. This study evaluates the impact of economic uncertainty on Pakistan's economic growth for the period between 2011M1 and 2020M5 through the recently developed EPU index. The ARDL and NARDL models are used to examine the long-term and short-term asymmetric impact of economic uncertainty on output. By summing up the whole analysis, we find that EPU negatively and significantly affects the economic growth of Pakistan. In addition, there is also asymmetric behavior of EPU in the short run only. The empirical findings of the study suggest that economic growth is more sensitive with respect to policy uncertainty in the short run as well as in the long run.

Keeping in view historical strands, high uncertainty during the recent recovery period has led to a relatively modest recovery. As economic theory suggests, when 
uncertainty increases, firms and consumers defer their future decisions during such a period, resulting in reduced economic activity. On the other hand, when uncertainty decreases, economic activity may rebound, but it does not happen instantly, like in Pakistan. The empirical evidence provided by the study suggests that economic uncertainty has disproportionate effects and that a decrease in uncertainty does not necessarily indicate an offset increase. As a result, the implications of uncertainty have led to a sustained decline in economic activity. To sum up, the current political and economic situation has raised the level of economic uncertainty in Pakistan.

\section{Recommendations}

Pakistan, as a developing country, should pay attention to the impact of the EPU on Pakistan's economic growth. First, there is a need to ensure political stability in the country to boost the confidence of investors and households. It will lower the cost of credit for households and firms. Hence, low inflation and high productivity levels will increase economic activity. Secondly, the country should build up coordination between macroeconomic policies to achieve its long-term goals. Finally, policymakers must play their part in reducing levels of uncertainty by estimating any future changes in the policy-regulatory environment and maintaining the flexibility to act quickly in the event of a major economic crisis.

Data availability The data that support the findings of this study are openly available at following: http:// www.policyuncertainty.com/, https://www.opec.org/opec_web/en/, Ejaz and Iqbal (2019).

\section{Declarations}

Conflict of interest There is no any conflict of interest between the authors.

\section{References}

Abbas A, Ahmed E, Husain F (2019) Political and economic uncertainty and investment behavior in Pakistan. Pak Dev Rev 58(3):307-331

Ahmad I, Qayyum A (2008) Effect of government spending and macro-economic uncertainty on private investment in services sector: evidence from Pakistan. Eur J Econ Financ Adm Sci 11:84-96

Ahmad I, Qayyum A (2009) Role of public expenditures and macroeconomic uncertainty in determining private investment in large scale manufacturing sector of Pakistan. Int Res J Finance Econ 26:34-40

Ahmad M, Khan Z, Rahman ZU, Khan S (2019) Does financial development asymmetrically affect $\mathrm{CO}_{2}$ emissions in China? An application of the nonlinear autoregressive distributed lag (NARDL) model (vol 9, pg 631, 2018). Carbon Manag 10(1):113-113

Aizenman J, Marion NP (1993a) Macroeconomic uncertainty and private investment. Econ Lett 41(2):207-210

Aizenman J, Marion NP (1993b) Policy uncertainty, persistence and growth. Rev Int Econ 1(2):145-163

Akber N, Paltasingh KR (2019) Is public investment complementary to private investment in Indian agriculture? Evidence from NARDL Approach. Agric Econ 50(5):643-655

Antonakakis N, Chatziantoniou I, Filis G (2014) Dynamic spillovers of oil price shocks and economic policy uncertainty. Energy Econ 44:433-447 
Arby MF (2008) Some issues in the national income accounts of Pakistan (rebasing, quarterly and provincial accounts and growth accounting). PhD Dissertation, Pakistan Institute of Development Economics, Islamabad

Asteriou D, Price S (2005) Uncertainty, investment, and economic growth: evidence from a dynamic panel. Rev Dev Econ 9(2):277-288

Baker SR, Bloom N, Davis SJ (2016) Measuring economic policy uncertainty. Q J Econ 131(4):1593-1636

Banerjee A, Marcellino M, Masten I (2005) Leading indicators for euro-area inflation and GDP growth. Oxf Bull Econ Stat 67:785-813

Barrero JM, Bloom N, Wright I (2017) Short and long run uncertainty (No. w23676). National Bureau of Economic Research

Bekiros S, Gupta R, Majumdar A (2016) Incorporating economic policy uncertainty in US equity premium models: a nonlinear predictability analysis. Financ Res Lett 18:291-296

Bhagat S, Ghosh P, Rangan SP (2013) Economic policy uncertainty and economic growth in India. Indian Institute of Management Bangalore. Working Paper Series 407

Bhatti MA, Muhammad AA, Iqbal W (2008) Impact of democracy, political instability, and policy uncertainty on private investment: a case study of Pakistan. Forman J Econ Stud 4:87-101

Bloom N (2009) The impact of uncertainty shocks. Econometrica 77(3):623-685

Bloom N, Bond S, Van Reenen J (2007) Uncertainty and investment dynamics. Rev Econ Stud 74(2):391-415

Brogaard J, Detzel A (2015) The asset-pricing implications of government economic policy uncertainty. Manag Sci 61(1):3-18

Bruno G, Lupi C (2004) Forecasting industrial production and the early detection of turning points. Empir Econ 29(3):647-671

Chen J, Jin F, Ouyang G, Ouyang J, Wen F (2019) Oil price shocks, economic policy uncertainty and industrial economic growth in China. PLoS ONE 14(5):e0215397

Choudhary MA, Pasha F, Waheed M (2020) Measuring economic policy uncertainty in Pakistan. MPRAPaper, vol No. 100013. University Library of Munich, Germany

Dakhlaoui I, Aloui C (2016) The interactive relationship between the US economic policy uncertainty and BRIC stock markets. Int Econ 146:141-157

Das D, Kumar SB (2018) International economic policy uncertainty and stock prices revisited: multiple and partial wavelet approach. Econ Lett 164:100-108

Ejaz M, Iqbal J (2019) Estimation and forecasting of industrial production index (No. 103). State Bank of Pakistan, Research Department

Fang L, Chen B, Yu H, Qian Y (2018) The importance of global economic policy uncertainty in predicting gold futures market volatility: a GARCH-MIDAS approach. J Futur Mark 38(3):413-422

Farooq A, Yasmin B (2017) Fiscal policy uncertainty and economic growth in Pakistan: role of financial development indicators. J Econ Coop Dev 38(2):1

Fatima A, Waheed A (2014) Economic uncertainty and growth performance: a macroeconomic modeling analysis for Pakistan. Qual Quant 48(3):1361-1387

Fountas S, Karanasos M (2006) The relationship between economic growth and real uncertainty in the G3. Econ Model 23(4):638-647

Fountas S, Karanasos M, Kim J (2006) Inflation uncertainty, output growth uncertainty and macroeconomic performance. Oxf Bull Econ Stat 68(3):319-343

Ghosh S (2020) Asymmetric impact of COVID-19 induced uncertainty on inbound Chinese tourists in Australia: insights from nonlinear ARDL model. Quant Financ Econ 4(2):343

Handley K, Limao N (2015) Trade and investment under policy uncertainty: theory and firm evidence. Am Econ J Econ Policy 7(4):189-222

Hanif MN, Iqbal J, Malik MJ (2013) Quarterisation of national income accounts of Pakitan. SBP working paper series, No. 54

Hettige H, Lucas RE, Wheeler D (1992) The toxic intensity of industrial production: global patterns, trends, and trade policy. Am Econ Rev 82(2):478-481

Ibrahim MH (2015) Oil and food prices in Malaysia: a nonlinear ARDL analysis. Agric Food Econ 3(1):1-14

Işık C, Sirakaya-Turk E, Ongan S (2020) Testing the efficacy of the economic policy uncertainty index on tourism demand in USMCA: Theory and evidence. Tour Econ 26(8):1344-1357

Jeong B (2002) Policy uncertainty and long-run investment and output across countries. Int Econ Rev 43(2):363-392 
Jiandong W, Khan MB (2018) The impact of economic policy uncertainty on the innovation in China: empirical evidence from autoregressive distributed lag bounds tests. Cogent Econ Financ 6(1): 1514929

Kang W, Ratti RA (2013) Structural oil price shocks and policy uncertainty. Econ Model 35:314-319

Kang W, Lee K, Ratti RA (2014) Economic policy uncertainty and firm-level investment. J Macroecon 39:42-53

Kang W, de Gracia FP, Ratti RA (2017) Oil price shocks, policy uncertainty, and stock returns of oil and gas corporations. J Int Money Financ 70:344-359

Karnizova L, Li JC (2014) Economic policy uncertainty, financial markets, and probability of US recessions. Econ Lett 125(2):261-265

Ko JH, Lee CM (2015) International economic policy uncertainty and stock prices: wavelet approach. Econ Lett 134:118-122

Lensink R, Bo H, Sterken E (1999) Does uncertainty affect economic growth? An empirical analysis. Weltwirtschaftliches Arch 135(3):379-396

Liang CC, Troy C, Rouyer E (2020) US uncertainty and Asian stock prices: evidence from the asymmetric NARDL model. N Am J Econ Financ 51:101046

Pastor L, Veronesi P (2012) Uncertainty about government policy and stock prices. J Financ 67(4):1219-1264

Raza SA, Shah N, Shahbaz M (2018) Does economic policy uncertainty influence gold prices? Evidence from a nonparametric causality-in-quantiles approach. Resour Policy 57:61-68

Ren Y, Guo Q, Zhu H, Ying W (2020) The effects of economic policy uncertainty on China's economy: evidence from time-varying parameter FAVAR. Appl Econ 52(29):3167-3185

Servén L (1998) Macroeconomic uncertainty and private investment in developing countries: an empirical investigation. Available at SSRN 597249. https://ssrn.com/abstract=597249

Serven L (2002) Real exchange rate uncertainty and private investment in developing countries. The World Bank

Shin Y, Yu B, Greenwood-Nimmo M (2014) Modelling asymmetric cointegration and dynamic multipliers in a nonlinear ARDL framework. Festschrift in honor of Peter Schmidt. Springer, New York, pp 281-314

Tam PS (2018) Global trade flows and economic policy uncertainty. Appl Econ 50(34-35):3718-3734

Wang Q, Sun X (2017) Crude oil price: demand, supply, economic activity, economic policy uncertainty and wars-from the perspective of structural equation modelling (SEM). Energy 133:483-490

Wang Y, Chen CR, Huang YS (2014) Economic policy uncertainty and corporate investment: evidence from China. Pac Basin Financ J 26:227-243

Wen J, Khalid S, Mahmood H, Zakaria M (2021) Symmetric and asymmetric impact of economic policy uncertainty on food prices in China: a new evidence. Resour Policy 74:102247

Yin L (2016) Does oil price respond to macroeconomic uncertainty? New evidence. Empir Econ 51(3):921-938

Publisher's Note Springer Nature remains neutral with regard to jurisdictional claims in published maps and institutional affiliations. 